BENM 2021

International Scientific and Practical Conference "Biotechnology, Ecology, Nature Management"

\title{
DETERMINING THE MAXIMUM FOOD DOSE FOR CYPRINUS CARPIO AFTER TRANSPLANTATION
}

\author{
Yu. A. Kuchikhin (a)*, A. S. Shavrin (b), A. A. Zyulkin (c), I. R. Selivanova (d) \\ *Corresponding author
}

(a) K.G. Razumovsky Moscow State University of Technologies and Management (the First Cossack University, 73, Zemlyanoy Val str., Moscow, Russia, kuchikhin@gmail.com

(b) K.G. Razumovsky Moscow State University of Technologies and Management (the First Cossack University) 73, Zemlyanoy Val str., Moscow, Russia

(c) K.G. Razumovsky Moscow State University of Technologies and Management (the First Cossack University) 73, Zemlyanoy Val str., Moscow, Russia

(d) K.G. Razumovsky Moscow State University of Technologies and Management (the First Cossack University), 73, Zemlyanoy Val str., Moscow, Russia, i.selivanova@mgutm.ru

\begin{abstract}
In commercial aquaculture, one of the most important indicators is the amount of feed applied and feed consumed. To achieve maximum growth and a low feed ratio, it is necessary to establish the amount of feed consumed by fish in different conditions. In aquaculture, the amount of feed per group of fish is based on the calculation of the biomass of the fish, taking into account its growth rate. Thus, the transfer of fish, transportation of under yearlings and yearlings from one farm to another is a strong stress for the fish. One of the acclimatization procedures in such conditions is the regulation of feeding and the use of special feed. Under such conditions, it is rather difficult to measure the primary food requirements, since there is still no data on the growth of fish under current conditions. This article presents a study of the maximum single dose of food for Cyprinus carpio after movement and acclimatization in the new environment.
\end{abstract}

2672-8575 (c) 2022 Published by European Publisher.

Keywords: Aquariums, concentration, Cyprinus carpio, diet, feed intake, feed 


\section{Introduction}

Aquaculture in the Russian Federation has shown commensurate growth over the past few years. The volume of aquaculture is growing by $300 \%$ according to the latest data (United Nations Food and Agriculture Organization, [FAO], 2018). Carp have been one of the most popular aquaculture species around the world. It is actively bred in the conditions of cage and pond farms, as well as in closed water supply installations. Transport is very stressful for fish and there is a lot of waste during transport (Flajšhans \& Hulata, 2007).

Fish feeding in aquaculture is an important technological element on which key fish-biological indicators depend, which significantly affect the cost of finished fish products (Dong et al., 2014). Competent and effective selection of feed and feed additives contributes to ensuring the production potential and significantly affects the cost of fish products obtained, which is a very important criterion for fish farming in industrial aquaculture (Iffat et al., 2020). For fish farming in closed water supply systems, where, being isolated from natural conditions, aquatic organisms are in an anthropogenic environment and may not receive the full range of required substances necessary to maintain health and effective growth (Vandeputte, 2003).

This, in turn, can cause various pathologies of the gastrointestinal tract (gastrointestinal tract) and a decrease in immunity. In particular, this problem is of greatest importance for juveniles, when at the moment of formation of the main systems and organs. The main growth potential of an individual is laid, which will certainly affect the quality of life and physiological parameters, and the described violations can lead to premature death of individuals, a decrease in growth rates and various disorders in the development of the body (Flajšhans \& Hulata, 2007; Nikiforov-Nikishin et al., 2021).

It is known that the productivity of fish is in direct proportion to the completeness of feeding. Microelements play an essential role in plastic processes, formation and construction of body tissues (Dobšíková et al., 2006). They are part of vitamins, enzymes, hormones, determine their activity and thus have a great effect on metabolism, which ultimately affects growth, development and reproductive capacity.

\section{Problem Statement}

After transport, fish require increased feed intake to recover from stress, however, excessive feed application disrupts the hydrochemical composition of the water. At the same time, insufficient feeding of fish, which is under the influence of stress factors, can lead to the development of various diseases.

\section{Purpose of the Study}

The aim of the work was to create a model setup for stabilizing the physical condition of fish and determining the optimal feed requirement for the species Cyprinus carpio. The task is to determine the maximum amount of food for groups of fish. 


\section{Research Methods}

For the experiment, a model installation was created that simulates adaptation-quarantine conditions. For this, five aquariums with a volume of 40 liters were taken. The water for the aquariums corresponded to the needs of the fish and was kept for 24 hours. Each aquarium has been fitted with Barbus Heater 50w heaters, designed for aquariums up to 60 liters and can be kept at temperatures between $20^{\circ} \mathrm{C}$ and $32^{\circ} \mathrm{C}$. The temperature of the sensors was adjusted to $23^{\circ} \mathrm{C}$. An internal filter Barbus Filter WP-310 with aeration function was also installed, with a capacity of up to $2001 / \mathrm{h}$ and suitable for aquariums up to 40 liters. The lighting throughout the experiment was natural, without the use of lamps (figure 1).

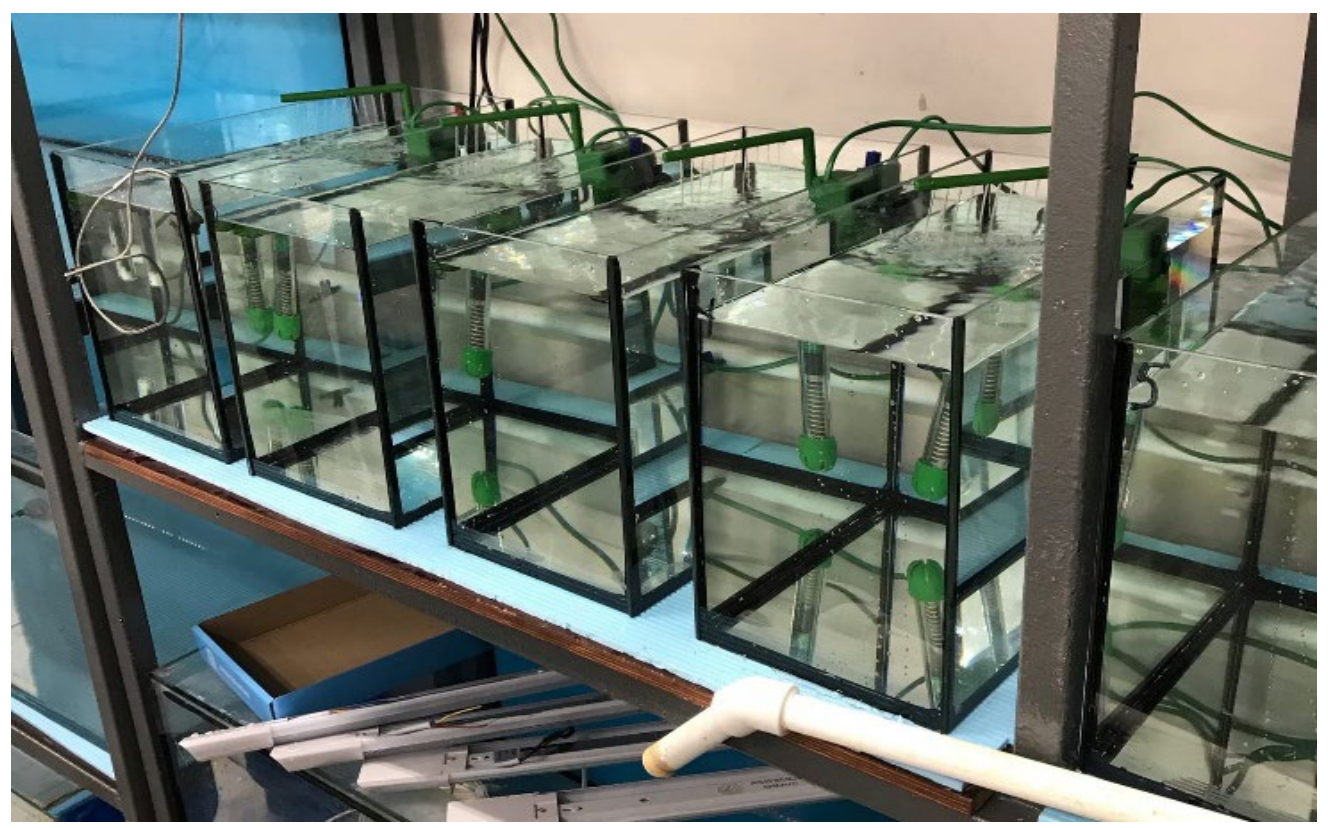

Figure 1. General view of the content aquariums

The fish were placed in thermo-boxes and transportation conditions were simulated for 2 hours. Then they were transferred to prepared aquariums, 5 individuals in each. Each fish was individually weighed on a DL-120 wp electronic scale to determine the total weight and average of one fish in all aquariums. The average fish weight is shown in table 1.

Table 1. Average weight in each group

\begin{tabular}{rrrrc}
\hline Group 1 & Group 2 & Group 3 & Group 4 & Group 5 \\
\hline $10,237 \pm 2,15$ & $10,0506 \pm 2,075$ & $10,6272 \pm 2,542$ & $10,1352 \pm 2,356$ & $10,2670 \pm 2,196$
\end{tabular}

The acclimatization time for the fish was 24 hours. The temperature of the medium is the same in every aquarium throughout the experiment. Alltech Coppens Pre Grower-18 food was used for the experiment, with a granule size of $2 \mathrm{~mm}$. The granule size is commensurate with the age characteristics of the fish. The nutritional value of the feed and its composition are presented in table 2. 
Table 2. Nutritional value of the feed

\begin{tabular}{ccccccc}
\hline Protein & Fats & Phosphorus & Fiber & Ash & Calcium & Sodium \\
\hline $45 \%$ & $18 \%$ & $1,39 \%$ & $1,7 \%$ & $8,5 \%$ & $1,7 \%$ & $0,4 \%$ \\
\hline
\end{tabular}

After weighing, the fish are divided into 5 experimental groups, each in an individual aquarium: group 1 - 1\% feed by weight of the fish; Group 2 - 2\% feed by weight of fish; Group 3 - 3.5\% of feed by weight of fish; Group $4-4.5 \%$ of feed by weight of fish; Group $5-6 \%$ of feed by weight of fish.

The volume of feed was determined by the calculation and experimental method and proceeded from the advisability of introducing such a volume. The food was weighed on an And GR-200 scale separately for each aquarium and placed in glass tubes.

In 1.5 hours, the food is completely consumed, but the food does not have time to be utilized from the gastrointestinal tract. After a specified time had elapsed, the digestive tract was removed from the fish and its contents were weighed. The contents are transferred to Petri dishes, weighed on the DL-12wp scale and the ratio of feed introduced into the aquarium and consumed is compared. The food that is pulled out of the digestive tract contains moisture. To determine the content of dry food in the suspended contents, two samples were taken from each aquarium. The samples were transferred to a glass bowl and placed in a temperature cabinet for 10 minutes at a temperature of 110 degrees. We took it out after drying and weighed it. After recalculation in accordance with the removed moisture, the weight of the feed was $50 \%+-5 \%$ of the wet content.

The results obtained for the consumed food in each aquarium are presented in table 3 .

Table 3. Food consumed by fish in different experimental groups

\begin{tabular}{cccc}
\hline & Group & Fish weight g & Feed weight \\
\hline 1 & Mean & 6,8972 & 0,1114 \\
& SD & 2,770843 & 0,718852 \\
2 & Mean & 6,0506 & 0,2324 \\
& SD & 2,375306 & 0,74278 \\
3 & Mean & 6,6272 & 0,3998 \\
& SD & 2,542346 & 0,697682 \\
4 & Mean & 6,1352 & 0,3636 \\
& SD & 2,356275 & 0,525922 \\
5 & Mean & 5,7066 & 0,3288 \\
& SD & 2,196704 & 0,71367 \\
\hline
\end{tabular}

\section{Findings}

In the case of the first two aquariums, the feed was consumed in full and the feed was insufficient for the fish. The amount of food in each aquarium is shown in Figure 2. 


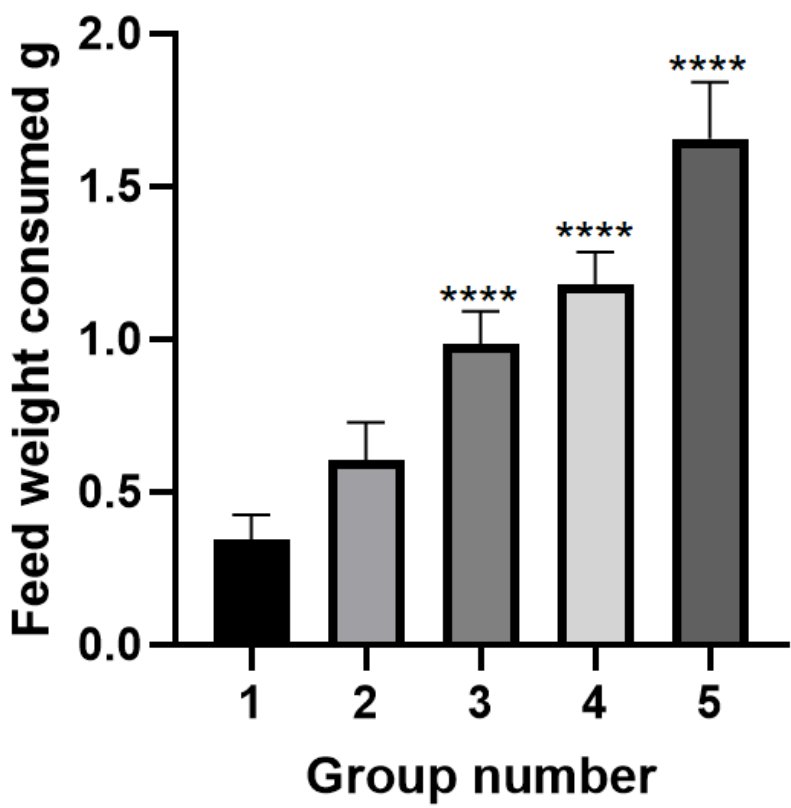

Figure 2. The amount of food consumed in each group. Comparison was made using non-paired Student's t-test $(\mathrm{P}<0.05)$

Based on the data obtained, the best indicator was achieved with the introduction of $3.5 \%$ of feed by weight of fish in-group No. 3. With $1.001 \mathrm{~g}$ applied, the consumed feed weight was $0.995 \mathrm{~g}$, which is $99.4 \%$ of the applied feed. The total amount of dry food consumed for each aquarium is shown in Table 4.

Table 4. Amount of consumed dry food in different groups

\begin{tabular}{cccccc}
$\begin{array}{c}\text { Group } \\
\text { number }\end{array}$ & $\mathbf{1}$ & $\mathbf{2}$ & $\mathbf{3}$ & $\mathbf{4}$ & $\mathbf{5}$ \\
\hline Weight g & 1 (completely consumed) & 1 (completely consumed) & 0,995 & 0,909 & 0,882 \\
\hline
\end{tabular}

The best indicator of food consumption was observed in-group No. 4, and amounted to $77.36 \%$ of the applied food, which is the best indicator among all control groups, and is $4.65 \%$ of the total weight of fish in this group.

In the case of groups 4 and 5, the fish did not react with an excess of feed, the amount of feed consumed decreased, and therefore, with an increase for feed introduced into the aquarium, the amount of consumption began to fall. The best rate of application is determined at around $3.5 \%$ by weight. As a result of the work, the maximum single dose of feed intake was determined.

Some studies have noted a positive dynamics of recovery of fish after long transport, with prolonged feeding with feeds with a high fat content (Albers et al., 1983). An important condition for successful acclimatization is compliance with the transportation conditions, the key of which is increased aeration of the transportation tanks (Hoseini et al., 2019; Hussain et al., 2015). It is also possible to use anesthetics to shrink the injured fish; however, anesthesia can also affect the immune characteristics of 
the fish. Another important condition for successful acclimatization is the quality of the water in which further fish breeding will take place (Nikiforov-Nikishin et al., 2020).

The conducted studies and the above-mentioned factors allow us to conclude that for successful acclimatization in new conditions after transportation, it is necessary to carry out complex measures, including the preparation of transportation tanks and a number of acclimatization procedures.

\section{Conclusion}

1. According to the data obtained in groups, one and two, feed consumption was insufficient, but consumed in full. Based on visual observation, the fastest feed consumption was observed in the first and second groups. This is due to competition for food within the species. Along with this, over-application of feed, as shown in groups 4 and 5, contributed to the slowest feed intake. From this, it is worth concluding that over-application of feed reduces its total consumption, and the introduction of too small a number accelerates.

2. Research and weighing of the contents of the digestive tract allows you to determine the maximum possible one-time feed consumption at around $3.5 \%$, which is optimal. When this dosage is applied, the speed and volume of feed consumption remain at high values.

3. The goal of the work was the initial feed rate baseline that was achieved. Further research is required in an industrial setting based on the type of aquaculture object.

\section{References}

Albers, C., Manz, R., Muster, D., \& Hughes, G. M. (1983). Effect of acclimation temperature on oxygen transport in the blood of the carp, Cyprinus carpio. Respiration physiology, 52(2), 165-179. https://doi.org/10.1016/0034-5687(83)90003-8

Dobšíková, R., Svobodová, Z., Blahová, J., Modrá, H., \& Velíšek, J. (2006). Stress response to long distance transportation of common carp (Cyprinus carpio L.). Acta Veterinaria Brno, 75(3), 437448. https://doi.org/10.2754/avb200675030437

Dong, Z., Nguyen, N. H., \& Zhu, W. (2014). Genetic evaluation of a selective breeding program for common carp Cyprinus carpio conducted from 2004 to 2014. BMC genetics, 16(1), 1-9. https://doi.org/10.1186/s12863-015-0256-2

Flajšhans, M., \& Hulata, G. (2007). Common carp-Cyprinus carpio. Genetic impact of aquaculture activities on native populations. In D. Corosetti, E., Garcia-Vasquez, \& E., Veerspoor (Eds.), Sixth Framework plan of the EC, final scientific report.

Hoseini, S. M., Yousefi, M., Hoseinifar, S. H., \& Van Doan, H. (2019). Cytokines' gene expression, humoral immune and biochemical responses of common carp (Cyprinus carpio, Linnaeus, 1758) to transportation density and recovery in brackish water. Aquaculture, 504, 13-21. https://doi.org/10.1016/j.aquaculture.2019.01.049

Hussain, T., Verma, A. K., Tiwari, V. K., Prakash, C., Rathore, G., Shete, A. P., \& Saharan, N. (2015). "Effect of water flow rates on growth of Cyprinus carpio var. koi (Cyprinus carpio L., 1758) and spinach plant in aquaponic system. Aquaculture International, 23(1), 369-384. https://doi.org/10.1007/s10499-014-9821-3

Iffat, J., Tiwari, V. K., Verma, A. K., \& Pavan-Kumar, A. (2020). Effect of different salinities on breeding and larval development of common carp, Cyprinus carpio (Linnaeus, 1758) in inland saline groundwater. Aquaculture, 518, 734658. https://doi.org/10.1016/j. aquaculture.2019.734658

Nikiforov-Nikishin, A. L., Nikiforov-Nikishin, D. L., Kochetkov, N. I., \& Tatarenko, P. Y. (2020). "Biocenosis of cold-water and warm-water biofilter in recirculating aquaculture system. IOP 
Conference Series: Earth and Environmental Science, 548(8), 082097. https://doi.org/10.1088/1755-1315/548/8/082097

Nikiforov-Nikishin, D. L., Nikiforov-Nikishin, A. L., Bugaev, O. G., \& Kochetkov, N. I. (2021). Temperature differentiation of aquatic microflora of a closed water supply system by the example of incubation of microbiological crops at 21 and $37^{\circ}$ C. IOP Conference Series: Earth and Environmental Science, 723(4), 042049. https://doi.org/10.1088/1755-1315/723/4/042049

United Nations Food and Agriculture Organization [FAO]. (2018). The State of World Fisheries and Aquaculture 2018: Meeting the sustainable development goals. FAO.

Vandeputte, M. (2003). Selective breeding of quantitative traits in the common carp (Cyprinus carpio): a review. Aquatic Living Resources, 16(5), 399-407. https://doi.org/10.1016/S0990-7440(03)000561 